\title{
A BAIXA REPRESENTATIVIDADE DA MULHER NA CÂMARA FEDERAL DOS DEPUTADOS: UM REFLEXO DA VIOLÊNCIA SIMBÓLICA
}

\author{
Marcely Alves Araújo ${ }^{1}$ \\ Elian Carmo Santana Pimentel ${ }^{2}$ \\ Isabella Boccardo ${ }^{3}$ \\ Marina Arantes de Souza ${ }^{4}$ \\ Maurício Martins Alves ${ }^{5}$ \\ Luiz Carlos Andrade de Aquino ${ }^{6}$ \\ Daniel Lipparelli Fernandez ${ }^{7}$
}

Resumo: Este texto aprecia os motivos da baixa representatividade da mulher na vida política brasileira, ressaltando que tal fato reflete uma violência simbólica, estabelecida principalmente através dos papeis pré-estipulados aos gêneros feminino e masculino. Busca-se, por meio do conteúdo apresentado, chamar a atenção para a necessidade de investimento em políticas públicas eficazes para inserção das mulheres no meio político. Nesse sentido, são apresentados dados estatísticos e gráficos, buscando apontar a realidade e reforçar a necessidade da desconstrução de pensamentos enraizados na cultura brasileira que inferiorizam a mulher. A partir do conceito proposto pelo sociólogo Pierre Bourdieu (violência simbólica), demonstra-se que a grande diferenciação entre os gêneros, persistente na sociedade brasileira se perfaz de forma implícita e sutil. O foco deste estudo se restringe à Câmara Federal dos Deputados brasileira, na qual se percebe quantitativa e ideologicamente que as mulheres ainda são sub-representadas. $A$ representação das mulheres na política brasileira se faz necessária para a garantia de seus direitos sociais, por meio da participação efetiva nas decisões do Estado, bem como para a manutenção da democracia. Palavras-chave: Mulher; Violência simbólica; Política.

\footnotetext{
1 Univap/Faculdade de Direito, Brasil. E-mail: marcely.araujo@outlook.com.

2 Univap/Faculdade de Direito, Brasil. E-mail: eliankarmo@gmail.com.

3 Univap/Faculdade de Direito, Brasil. E-mail: bellaboccardo@gmail.com.

4 Univap/Faculdade de Direito, Brasil. E-mail: marina.arantes7@gmail.com.

5 Univap/Faculdade de Direito, Brasil. E-mail: mmalves@univap.br.

6 Univap/Faculdade de Direito, Brasil. E-mail: aquino@univap.br.

7 Univap/Faculdade de Direito, Brasil. E-mail: fernandez@univap.br.
} 